\title{
Deposition and Electrochemical Corrosion Behavior of Electroless Ni-P/Ni-W-P Duplex Plating on Mild Steel Substrate
}

\author{
Oloyede Olamilekan Razaq ${ }^{1}$, Zhu Liu ${ }^{1}$ and Hong Liu ${ }^{2}$ \\ 1. Corrosion and Protection Centre, School of Materials, The University of Manchester, ManchesterM13 9PL, United Kingdom
}

2. School of Mechanical and Automobile Engineering, Shandong Polytechnic University, Ji'nan 250100, P.R. China

Received: January 16, 2014 / Accepted: February 10, 2014 / Published: February 25, 2014.

\begin{abstract}
The emergence of electroless Ni-P based ternary coatings and consequence duplex deposition possibilities, now offer more excellent corrosion and functional properties in acidic and alkaline environment. In this study, medium and high phosphorus Ni-P and duplex Ni-W-P coatings were produced and sequentially deposited on mild steel using plating baths with $10 \mathrm{~g} / \mathrm{L}$ and $25 \mathrm{~g} / \mathrm{L}$ of sodium hypophosphite as reducing agent (RA) with composition of the resulting deposits to be $91.5 \mathrm{Ni}$ : $8.5 \mathrm{P}$ and $87.6 \mathrm{Ni}$ : $12.4 \mathrm{P}$, respectively. From the field-emission scanning electron microscope (FE-SEM) examination, the deposit morphology was found to change from nodular with some surface porosity to become more dense and smoother after heating treatment between $200-600{ }^{\circ} \mathrm{C}$. The cross-section reveals firm adhesion of the as-plated and the merging of the top duplex layers of the heat treated sample as a result of tungsten diffusion. The potentiodynamic polarization test shows that the coating demonstrated significant improvement of corrosion resistance in $3.5 \% \mathrm{NaCl}$ solution with optimum performance at $600{ }^{\circ} \mathrm{C}$. The noted improved corrosion resistance of the coating came as a result of annealing which strengthened the layer and broaden its application.
\end{abstract}

Key words: Electroless plating, Ni-W-P, duplex coating, heat treatment, corrosion, electrochemical potential.

\section{Introduction}

Electroless nickel based coatings possess certain distinct features which make them very useful in virtually every domain due to their excellent properties such as high hardness, wear and especially corrosion resistance which has drawn more attention towards them recently [1-3]. Basically, as plated Ni-P based coatings can be fully amorphous or mixed with nanocrystalline structure, with a coarse morphology depending on the phosphorus content and alloying elementsfor the desired functional performance [4-6]. The commercial applications of Ni-P based coatings, is widening with introduction or co-depositing of specific elements or composites such as: $\mathrm{W}, \mathrm{Mo}, \mathrm{Cu}, \mathrm{Al}_{2} \mathrm{O}_{3}$,

Corresponding author: Oloyede Olamilekan Razaq, Ph.D., research fields: corrosion and protection. E-mail: engrlekanoloyede@yahoo.com.
$\mathrm{ZrO}_{2}$ and many others third elements and composites into the binary matrix of nickel-phosphorus that has resulted in its better functional and high temperature corrosionresistance properties [1]. Many multi-layered high grade alloy coatings have already been developed using electrolytic-deposition which is a proven technique to prepare such coatings [1]. In their work, Jeong et al. [3], had successfully produced Ni-P/Ni-B as well as other electroless Ni-P graded coatings on different substrates with better uniformity than the former. They concluded that the multilayered Ni-P/Ni-B coating is better in the case of Ni-P as outer layer instead of Ni-B as top layer. Similarly, Liu et al. [6] reported that the corrosionproperty of Ni-P based ternary graded coatings depends largely on the type and content of the added component. This study takes a critical look on the electroless deposition, 
crystallization and corrosion behavior of duplex Ni-P-W outer layer on single inner Ni-P layer on mild steel substrate, obtained by series immersion in two separate electroless plating baths as illustrate in Fig. 1 above. The enhanced corrosion resistance was achieved by heat treatment using controlled furnace annealing in Argon. The needed post heat treatment ranges from $200{ }^{\circ} \mathrm{C}$ to $600{ }^{\circ} \mathrm{C}$. At higher temperature (approximately $370{ }^{\circ} \mathrm{C}$ ), the heat treatment caused precipitation of $\mathrm{Ni}_{3} \mathrm{P}$ phase along with its metastable forms, which eventually enhances the adhesion bonding between the coatings and the substrate [6], this aspect to the best knowledge of the authors has received very little or no attention from researchers so far. The purpose of the duplex Ni-W-P layer on Ni-P coating can be explained by the fact that Ni-W-P has better properties in terms of corrosion and wear than
Ni-P which in turns, has better adhesion/contact with the mild steel substrate, so that it acts as better intermediate layer [7-9]. The improved corrosion resistance of this coating is due largely to the huge amount of grain boundary diffusion paths provided by the nanostructure of the $\mathrm{Ni}_{3} \mathrm{P}$ and crystalline $\mathrm{Ni}$ at high temperature, caused by the furnace annealing especially if air cooled, which favored the formation of the dense nickel-tungsten and nickel oxide films on the surface [10-13].

\section{Experiments}

Fig 1, shows a mini-prototype bath for electroless plating with compositions and operating conditions outlined in Table 1 . The mild steel substrate was $1.5 \times$ $1.0 \times 1.0 \mathrm{~cm}$ in size. Full detail on this plating procedure can be found in any of Refs. [4, 13-15]. For

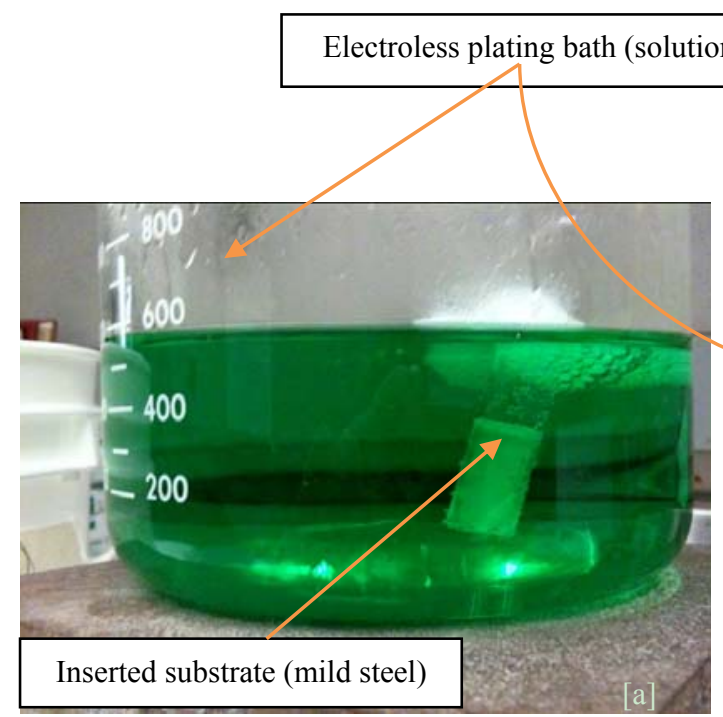

(a)

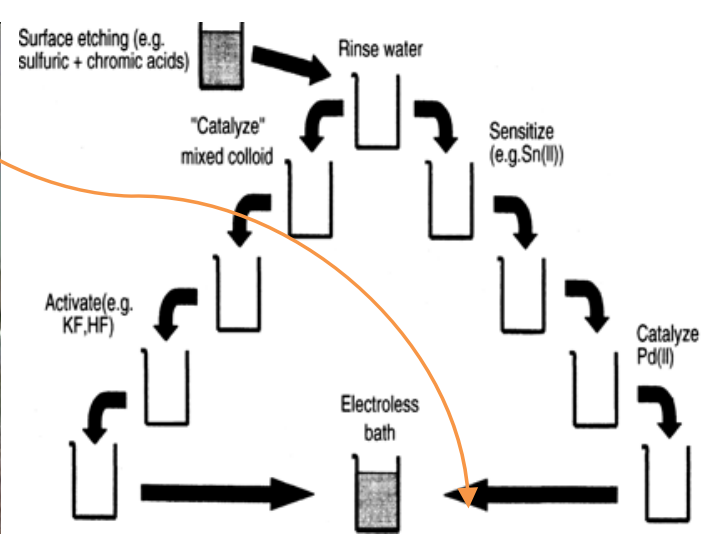

(b)

Fig. 1 (a) Typical electroless plating bath and (b) sequential insertion for multi-layer coatings.

Table 1 Composition of electroless bath used for Ni-P/Ni-W-P.

\begin{tabular}{lll}
\hline Chemical compound (name and formula) & & Concentration $(\mathrm{g} / \mathrm{L})$ \\
\cline { 2 - 3 } & Ni-P & Ni-W-P \\
\hline Nickel sulfate, $\mathrm{NiSO}_{4} \cdot 6 \mathrm{H}_{2} \mathrm{O}$ & 24 & 20 \\
Sodium hypophosphite, $\mathrm{NaH}_{2} \mathrm{PO}_{2} \cdot \mathrm{H}_{2} \mathrm{O}$ & 22 & 30 \\
Sodium citrate, $\mathrm{Na}_{3} \mathrm{C}_{6} \mathrm{H}_{5} \mathrm{O}_{7} \cdot 2 \mathrm{H}_{2} \mathrm{O}$ & 18 & 16 \\
Ammonium chloride, $\left(\mathrm{NH}_{4}\right)_{2} \mathrm{Cl}$ & 14 & 14 \\
Citric acid, $\mathrm{C}_{6} \mathrm{H}_{8} \mathrm{O}_{7} \cdot \mathrm{H}_{2} \mathrm{O}$ & 8 & 8 \\
Sodium tungsten, $\mathrm{Na}_{2} \mathrm{WO}_{4} \cdot 2 \mathrm{H}_{2} \mathrm{O}$ & 5 & - \\
\hline
\end{tabular}

Operating conditions: -Ni-P-W: $\left(91^{\circ} \mathrm{C} ; \mathrm{pH}\right.$ 9.5) \&Ni-P: $\left(85^{\circ} \mathrm{C} ; \mathrm{pH} 4.6\right)$. 
effective deposition, good sample pre-plating procedure was observed. Ni-P layer was first deposited, followed by double coating of Ni-W-P to obtain the duplex layers in sequence on top of the inner Ni-P deposit for an average of $1 \mathrm{~h}$ each. At the end of each electroless deposition, the samples were removed cleansed, dried weighed and re-immersed into the bath solution for the same period of time to ensure equal coating thickness. The SEM micrograph of the morphology and cross-section of the as-plated sample are as shown in Fig. 2.

The as-plated samples of the electroless deposition, exhibit good appearance and uniform coating thickness as expected contrary to a typical electrolytic deposit as compared in the schematic diagram in Fig. 3; showing even distribution of the coating layer over the substrate irrespective of the geometry, nature and size of such substrate. The heat treatment was carried out in a tube furnace in Argon environment to prevent severe oxidation which is difficult to avoid at elevated temperature. The annealing temperature ranges from $200{ }^{\circ} \mathrm{C}$ to $600{ }^{\circ} \mathrm{C}$ with 1 hour holding time for each temperature at 100 unit interval and each sample was furnace cooled to room temperature before removal. Energy dispersive analysis X-ray spectroscopy (EDX) was used to determine elemental compositions of the alloy coatings. Detailed X-ray diffraction (XRD) was conducted using Philip diffract meter with monochromatic $\mathrm{Cu}-\mathrm{K} \alpha$ radiation.

The peaks of XRD patterns were fitted using Philip

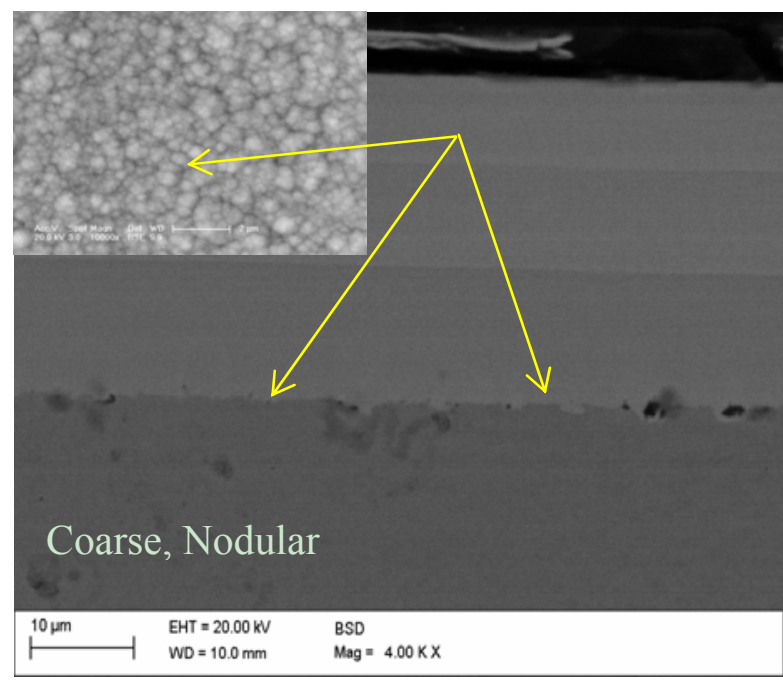

(a)

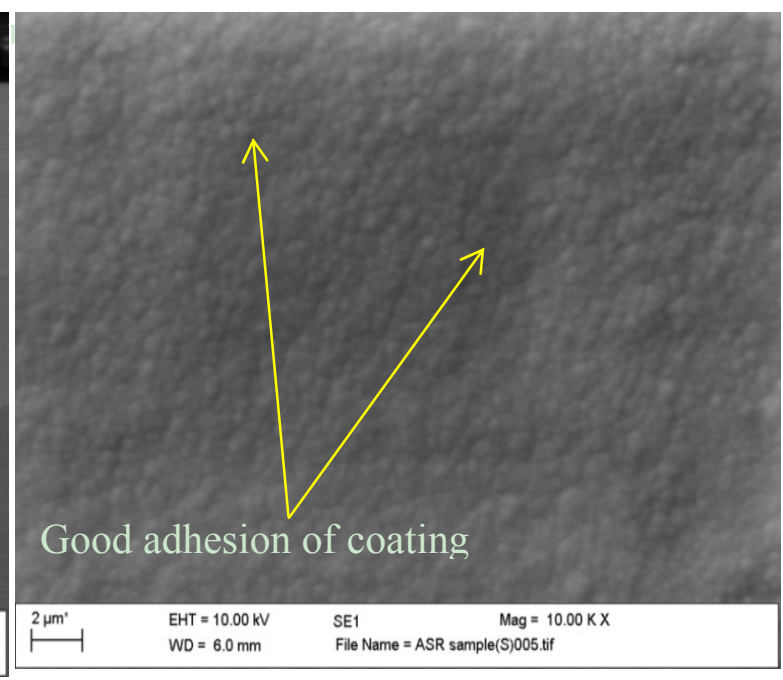

(b)

Fig. 2 SEM micrographs of the coating showing;(a) morphology and (b) cross-section.

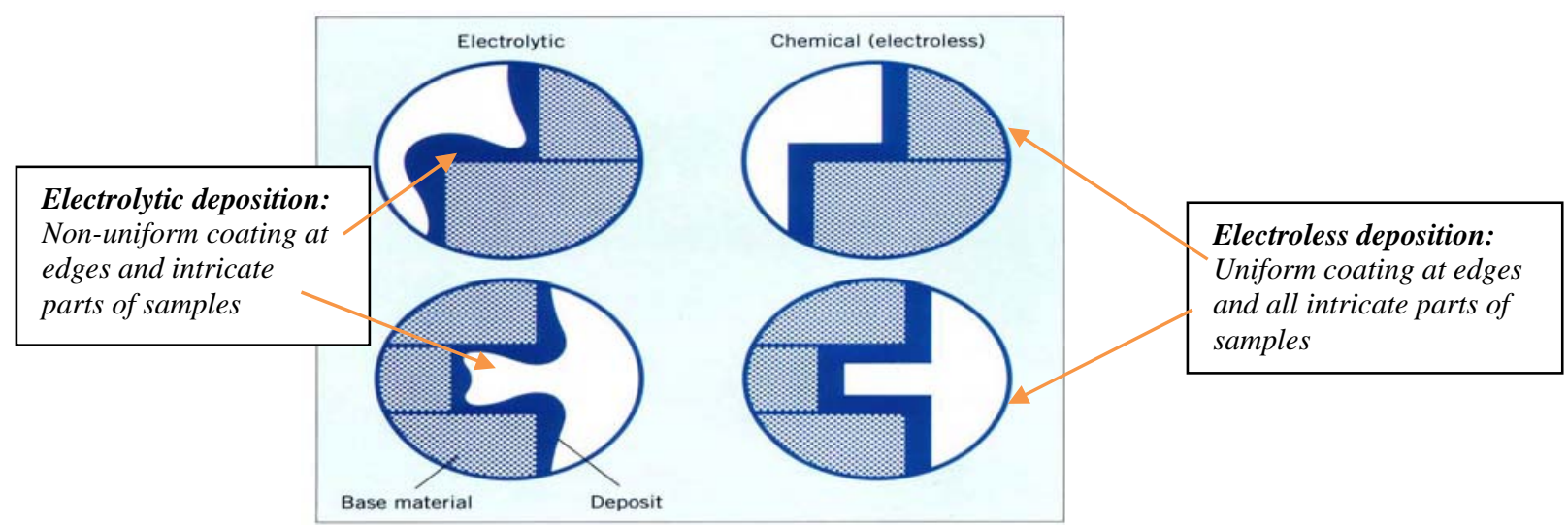

Fig. 3 Schematic diagram illustrating electrolytic and electroless deposition differences. 
APD software after subtracting the background to obtain the integrated intensities of the individual phases, amorphous, nickel and Ni3P and to further determine the volume fractions, represented by the ratio of Iamor/Itotal, INi/Itotal and $\mathrm{INi3P} / \mathrm{Ito}_{\text {tal }}$. The degree of crystallization, grain size and microstrain of individual phases from the XRD profiles were estimated, compared and to be discussed thereafter.

\section{Experimental Results}

\subsection{Coating Surface Morphologies and Elemental} Composition:

In addition to SEM micrograph in Fig. 2, the compositional analysis of the as-plated and heat treated samples shown in Fig. 4a; revealed that the outer duplex layers consisted of Ni-1.6W-8.5P (wt. \%) and inner single layer was found to be Ni-8.3P (Table 2); while that of the inner layer is found to be Ni-12.4P. Also the smart mapping in Fig. $4 \mathrm{~b}$ shows the uniformity of the elemental composition of the deposition. The thickness for each layer is approximately $10 \mu \mathrm{m}$, as shown in Fig. $2 \mathrm{~b}$ and the layers are distinct.

Fig. 4a shows the surface morphologies of the top-most (Ni-W-P) layer of the coating before heat treatment. The as plated coating (SEM/EDX micrographs in Figs. 4 and 5) is rather compact without visible defects such as porosity and represent a typical cauliflower-like morphology. Meanwhile, after heat treatment spanning from $200{ }^{\circ} \mathrm{C}$ to $600{ }^{\circ} \mathrm{C}$ noticeable morphological changes were observed due to microstructural changes as a result of thermal agitation, phase transformation and stress relieve on the surface of the coating with increase in temperature as shown in Figs. 6a-6c, this changes brought behavioral changes on the coating.

\subsection{Corrosion Behavior}

\subsubsection{Potentiodynamic Polarization Test}

Fig. 6 shows the potentiodynamic polarization curves for as-plated and all heat treated samples in 3.5 wt.\% NaCl. Table 3, presents the values of corresponding corrosion potential $E_{\text {corr }}$ and the corrosion current density $i_{\text {corr }}$ at different annealing

Table 2 Elemental composition (outer layer).

\begin{tabular}{|c|c|c|c|}
\hline \multirow{2}{*}{ Element } & Ni-W-PDuplex layer & Ni-PInner layer & Other traceable elementpresent in the coating: \\
\hline & \multicolumn{2}{|c|}{ Weight $\%$} & Molybdenum \\
\hline PK & 8.5 & 12.4 & Calcium \\
\hline $\mathrm{NiK}$ & 90.1 & 87.6 & Iron \\
\hline WM & 1.4 & - & Oxygen \\
\hline Totals & 100.00 & 100.00 & Carbon \\
\hline
\end{tabular}
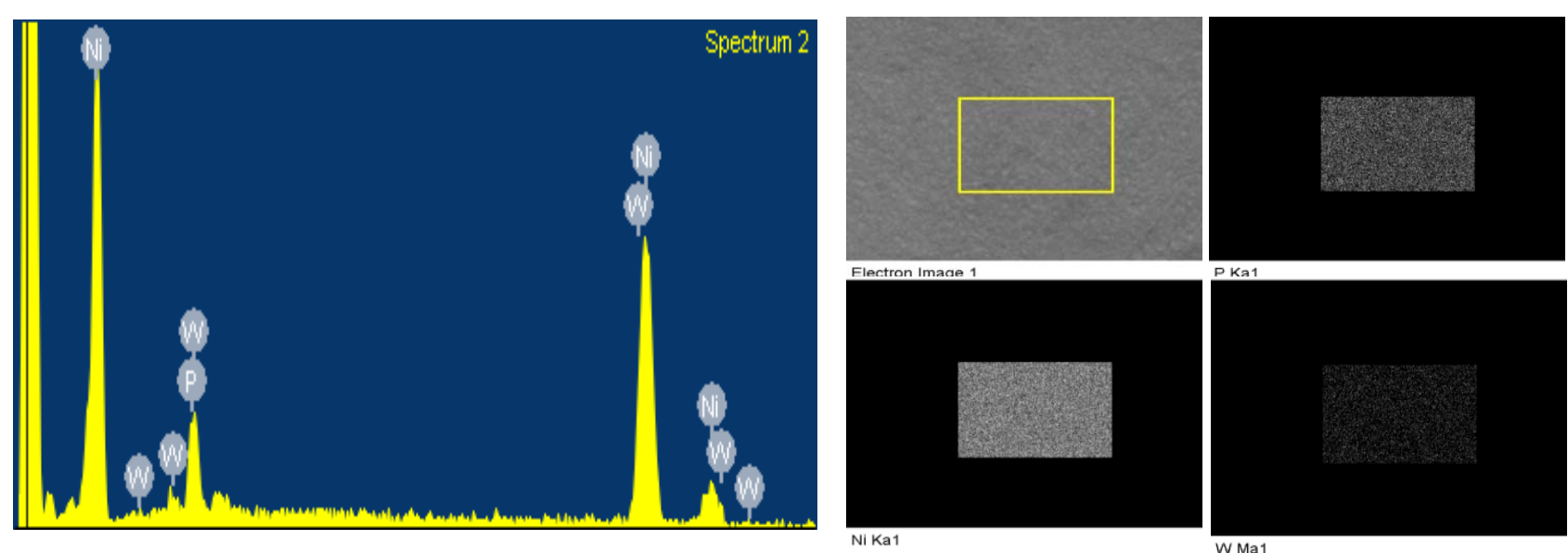

Fig. 4 EDX spectrum indicating elements present in the outer coating layer (surface). 


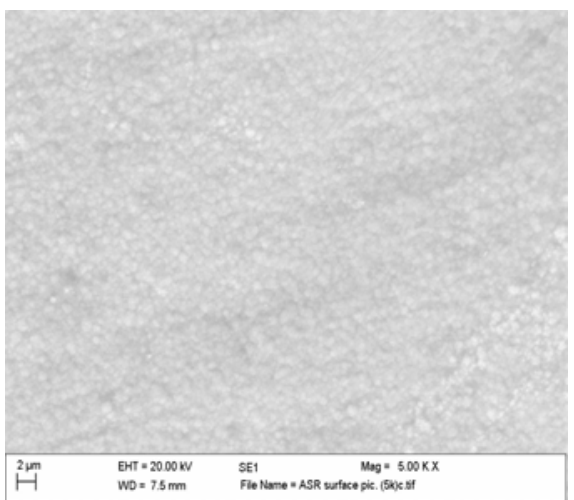

(a)

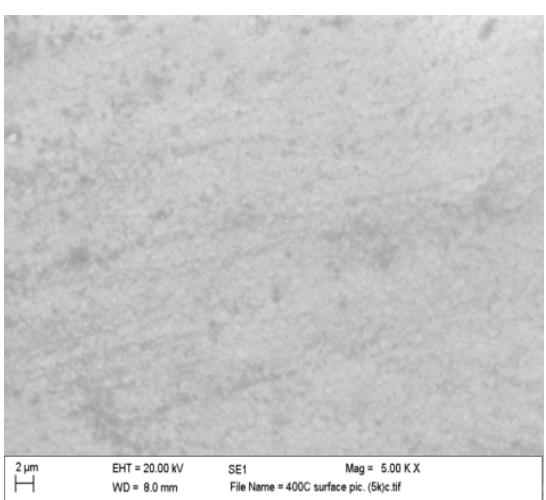

(b)

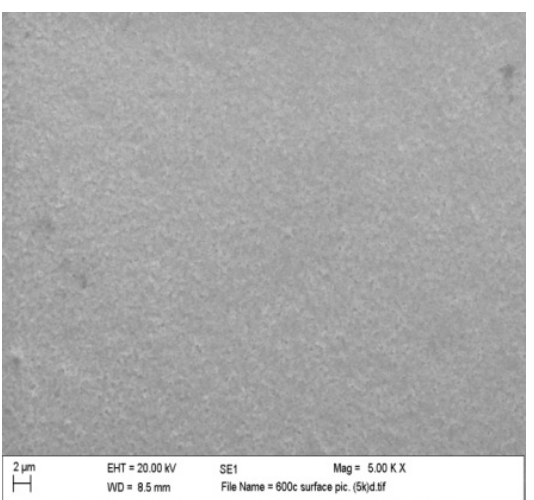

(c)

Fig. 5 SEM micrographs of (a) as plated; (b) $400{ }^{\circ} \mathrm{C}$ and (c) $600{ }^{\circ} \mathrm{C}$ heated treated samples.

Table 3 Corrosion characteristic of As-plated and heat treated samples in $3.5 \% \mathrm{NaCl}$.

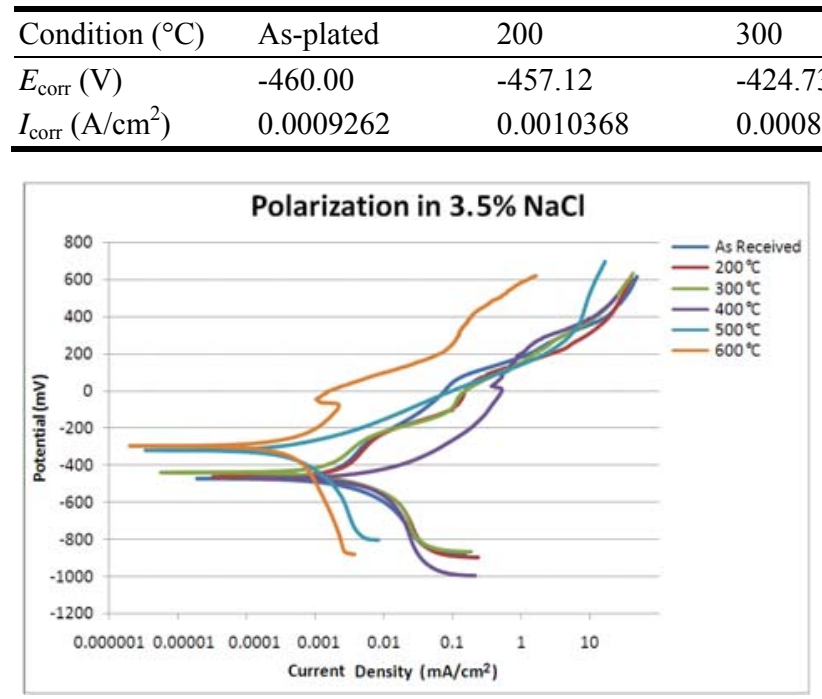

Fig. 6 Polarization curves of Ni-P/Ni-W-P duplex coating in 3.5 wt. \% $\mathrm{NaCl}$ solution.

temperatures. No passivation can be seen in any circumstances. The curves revealed a progressive increase of corrosion potential accompanied by thedecrease of anodic current density, indicating the improvement of corrosion resistance with increasing annealing temperature. It is evident from previous research works that nickel based alloy coatings have preferential dissolution of nickel which occurs at opencircuit potential, leading to the enrichment of phosphorus on the surface layer [8-10]. Then the enriched phosphorus surface reacts with water to form a layer of adsorbed hypophosphite anions $\left(\mathrm{H}_{2} \mathrm{PO}^{2-}\right)$. This layer in turn will block the supply of water to the electrode surface, thereby preventing the hydration of nickel [6]; which often considered being the first step to form either soluble $\mathrm{Ni}^{2+}$ species or a passive nickel film [10]. This suggestsformation of nanocrystallined Ni phase which enhances corrosion performance.

During electroless plating, the deposition process is accompanied by hydrogen evolution. The hydrogen atoms are occluded in as-plated deposits, generating internal tensile stress within the coating. Hence, when the coating is subjected to heat treatment, relief of the tensile stress is expected, this hydrogen elimination occur around $200{ }^{\circ} \mathrm{C}$ and the coating exhibits the same corrosion resistance up to $300{ }^{\circ} \mathrm{C}$. Meanwhile, the residual stress in the coatings between $400-600{ }^{\circ} \mathrm{C}$ is mainly transformation stress. At $400{ }^{\circ} \mathrm{C}$, the transformation stress is highest; then it decreases with increment of temperature due to grain growth. This is in agreement with the fact that the value of $i_{\text {corr }}$ is highest at $400{ }^{\circ} \mathrm{C}$, due to formation of micro-galvanic grain boundaries cell, along with phase boundaries between the $\mathrm{Ni}_{3} \mathrm{P}$ and the matrix (the crystalline $\mathrm{Ni}$ ). This explains the worse corrosion resistance of the coating at $400{ }^{\circ} \mathrm{C}$, due to appearance of maximum porosity at this particular temperature. The reduction of $i_{\text {corr }}$ at $500{ }^{\circ} \mathrm{C}$ and $600{ }^{\circ} \mathrm{C}$ might be attributed to the significant reduction of porosity, and formation of thin 
layer of nickel oxide ( $\mathrm{NiO})$ which is believed to be beneficial to the reduction of corrosion current densities. Fig. 7, shows the difference in the corrosion behavior of $600{ }^{\circ} \mathrm{C}$ heat treated sample with oxide and without the oxide film. Although the coating treated at $400{ }^{\circ} \mathrm{C}$ may show a similar amount of $\mathrm{Ni}_{3} \mathrm{P}$ phase, the formation of most pores at this particular temperature should be mainly responsible for the worst corrosion resistance observed.

\subsubsection{Electrochemical Impedance Spectroscopy Test}

Fig. 8 shows the Nyquist plots obtained for as-plated and heat treated coating in $3.5 \% \mathrm{NaCl}$ at their respective open circuit potentials. All the curves appear to be similar (Nyquist plots), consisting of a single semi-circle in the high frequency regions signifying the charge controlled reaction. In general, these Nyquist diagrams show a semi-elliptic arc in theinvestigated frequency range. Meanwhile, it should be noted that although these curves appear to be similar with respect to their shape, they differ in their sizes. The axial radius of this semi-elliptic arc is sharply increased with the gradual increase in the annealing temperature. In general, these Nyquist diagrams show a semi-elliptic arc in the investigated frequency range. This implies that the same fundamental processes must be occurring on all these coatings butover a different area in each condition as recorded by Kumar and Balaraju et al. [2, 12]. The occurrence of a single semi-circle in the Nyquist plots indicates that the corrosion process of these coatings involves a single time constant. A similar conclusion of the existence of a single time constant has been reported by Agarwala and Younes et al. [11].

The electrical model that can be used to simulate this type of electrochemical behavior is given in Fig. 9. The charge transfer resistance $\left(R_{c t}\right)$ is represented by the resistance of electron transfer during electrochemical reaction course. The double layer capacitance $\left(\mathrm{C}_{\mathrm{dl}}\right)$ can be correlated to the delamination of the coating. Solution resistance $\left(R_{s}\right)$ is referred to the resistance between the work electrode and reference electrode.

The values of charge transfer resistance $\left(\mathrm{R}_{\mathrm{ct}}\right)$ anddouble layer capacitance $\left(\mathrm{C}_{\mathrm{dl}}\right)$ were determined

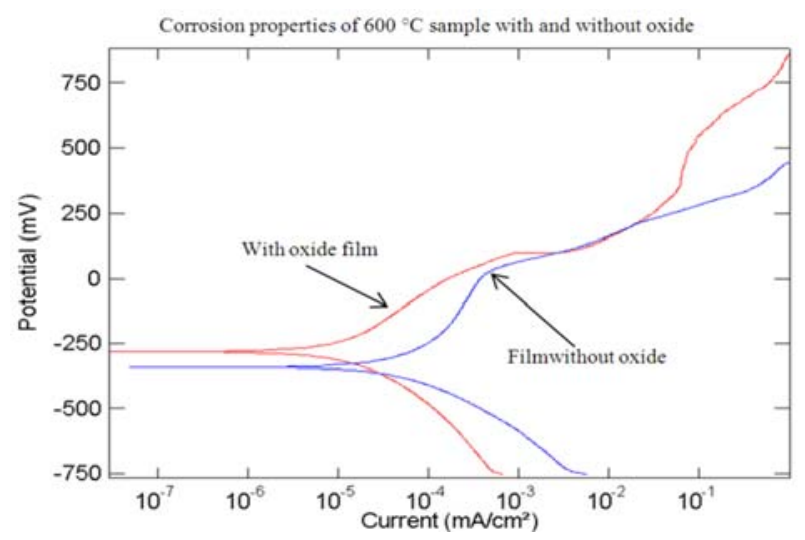

Fig. 7 Corrosion behavior of heat treated sample with or without oxide film layer.

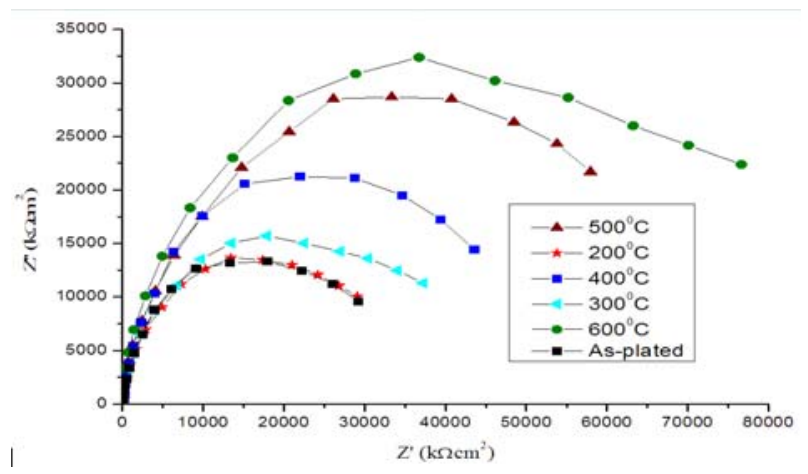

Fig. 8 Nyquist plot for as-plated and heat treated samples in 3.5 wt. \% NaCl.

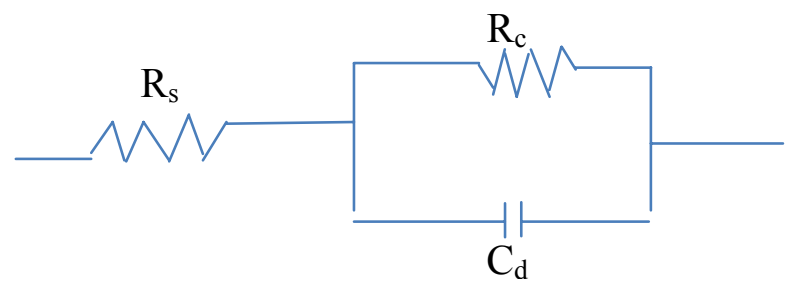

Fig. 9 Electrical circuit model to fit electrochemical impedance spectroscopy data.

Table 3 Electrochemical parameters from EIS data of as-plated \& heated treated samples.

\begin{tabular}{lllllll}
\hline & As plated & $200\left({ }^{\circ} \mathrm{C}\right)$ & $300\left({ }^{\circ} \mathrm{C}\right)$ & $400\left({ }^{\circ} \mathrm{C}\right)$ & $500\left({ }^{\circ} \mathrm{C}\right)$ & $600\left({ }^{\circ} \mathrm{C}\right)$ \\
\hline $\mathrm{R}_{\mathrm{ct}}\left(\Omega \cdot \mathrm{cm}^{2}\right)$ & 13,934 & 18,172 & 24,457 & 52,903 & 61,824 & 72,352 \\
$\mathrm{C}_{\mathrm{dl}}\left(\mu \mathrm{F} / \mathrm{cm}^{2}\right)$ & 38,334 & 32,952 & 30,652 & 28,154 & 6,795 & 3,823 \\
\hline
\end{tabular}


fromNyquist plot by fitting semicircle using $Z_{\text {sim }} 3.20$ software. Table 3 shows $\mathrm{R}_{\mathrm{ct}}$ and $\mathrm{C}_{\mathrm{dl}}$ obtained for As-plated and heat treated electroless Ni-P/Ni-W-P duplex coating.

\section{Conclusions}

Comparing electrochemical parameters and the confirmation from EIS results, it can be seen that because as-plated coating is nano-crystalline in nature, it has more grain boundaries, hence it is less protective. However, by increasing heat treatment temperatures from $200{ }^{\circ} \mathrm{C}$ to $600{ }^{\circ} \mathrm{C}$, the coating becomes denser and less porous and this is denoted by $\mathrm{C}_{\mathrm{dl}}$ values in Table 3 . At $200{ }^{\circ} \mathrm{C}$, there is grain growth that reduces grain boundaries and its corrosion properties are better than as-plated sample. At $600{ }^{\circ} \mathrm{C}$ and $400{ }^{\circ} \mathrm{C}$ it is expected that alloys consist of two constituents: crystals of the nickel-rich phase and the nickel phosphide phase. It can be seen that the as-plated is not continuous due to micro-pores, this explain the non-homogeneities (grain boundaries and second phase), which are active sites for corrosion attack. At $400{ }^{\circ} \mathrm{C}$ the formation of second phases of nickel phosphide causes increase phase boundaries but as the temperature increases, there is tremendous grain growth which enhances corrosion resistance of the coating at these higher temperatures. Hence, the grain growth at this temperatures triumph over the formation of metastablephases and the corrosion resistance increases. At $600{ }^{\circ} \mathrm{C}$, corrosion resistance increases compare to $400{ }^{\circ} \mathrm{C}$; this is in compromise to mechanical properties of the coating such hardness and wear which are optimal at $400{ }^{\circ} \mathrm{C}[14]$.

\section{References}

[1] B.S. Geng, W. Y.H. Wei, L.F. Hou, S. Li, Study on the microstructure and properties of electroless Ni-W-P plating on stainless steel, Rare Metal Materials and Engineering 38 (2009) 71-75.

[2] P.S. Kumar, P.K. Nair, Studies on crystallization of electroless Ni-P deposits, Journal of Materials Processing Technology 56 (1-4) (1996) 511-520.

[3] D.H. Jeong, U Erb, K.T. Aust, G. Palumbo, Effect of heat treatment on the electrodeposited nanocrystalline Ni-P coatings. Metastable, Mechanically Alloyed and Nanocrystalline Materials (2003) 635-642.

[4] X.M. Chen,G.Y. Li,J.S. Lian, Deposition of electroless Ni-P/Ni-W-P duplex coatings on AZ91D magnesium alloy, Transactions of Nonferrous Metals Society of China 18 (2008) S323-S328.

[5] W. Sha, X. Wu, K.G. Keong, Electroless Copper and Nickel-Phosphorus Plating: Processing, Characterisation and Modelling, 1st ed., Woodhead Publishing Limited, Cambridge, 2011, p. 285.

[6] Z. Liu, H. Liu, F. Viejo, Z. Aburas, Laser-induced microstructural modification for corrosion protection, in: Proceedings of the Institution of Mechanical Engineers Part C: Journal of Mechanical Engineering Science 224 (C5) (2010) 1073-1085.

[7] H. Liu, R.X. Guo, Y. Zong, B.Q. He, Z. Liu, Microstructure and corrosion performance of annealed electroless Ni-W-P coatings, Surface \& Coatings Technology 204 (9-10) (2010) 1549-1555.

[8] H. Liu, R.X. Guo, Y. Zong, B.Q. He, Z. Liu, Comparison of microstructure and residual stress characteristics of electroless Ni-W-P coatings annealed with a laser and a furnace, Surface \& Coatings Technology 206 (8-9) (2012) 2380-2387.

[9] H. Li, H. Chen, S. Dong, J. Yang, J.F. Deng, Study on the crystallization process of Ni-P amorphous alloy, Applied Surface Science 125 (1) (1998) 115-119.

[10] H. Liu, R.X. Guo, Y. Zong, B.Q. He, Z. Liu, Comparative study of microstructure and corrosion resistance of electroless Ni-W-P coatings treated by laser and furnace-annealing, Transactions of Nonferrous Metals Society of China 20 (6)(2010) 1024-1031.

[11] R.C. Agarwala,Studies on electroless coatings, Diffusion in Materials: Dimat 2004, Pts 1 and 2, 2005, pp. 952-957.

[12] J.N. Balaraju, S.M. Jahan, A. Jain, K.S. Rajam, Structure and phase transformation behavior of electroless Ni-P alloys containing tin and tungsten, Journal of Alloys and Compounds 436 (1-2) (2007) 319-327.

[13] B. Szczygiel,A. Turkiewcz,J. Serafinczuk, Surface morphology and structure of Ni-P, Ni-P-ZrO ${ }_{2}, \mathrm{Ni}-\mathrm{W}-\mathrm{P}$, Ni-W-P-Z $\mathrm{ZO}_{2}$ coatings deposited by electroless method. Surface \& Coatings Technology 202 (9) (2008) 1904-1910.

[14] O. Younes, L. Zhu, Y. Rosenberg, Y. Shacham-Diamand, Electroplating of amorphous thin films of tungsten/nickel alloys, Langmuir 17 (26) (2001) 8270-8275.

[15] A.M. Pillai, A. Rajendra, A.K. Sharma, Electrodeposited nickel-phosphorous (Ni-P) alloy coating: an in-depth study of its preparation, properties, and structural transitions, Journal of Coatings Technology and Research 9 (6) (2012) 785-797. 